\title{
Perceived stress at transition to workplace: a qualitative interview study exploring final-year medical students' needs
}

This article was published in the following Dove Press journal:

Advances in Medical Education and Practice

14 January 2016

Number of times this article has been viewed

\author{
Tobias R Moczko 1,2,* \\ Till J Bugaj',* \\ Wolfgang Herzog' \\ Christoph Nikendei' \\ 'Department for General Internal and \\ Psychosomatic Medicine, University \\ Hospital of Heidelberg, Heidelberg, \\ ${ }^{2} \mathrm{School}$ of Medicine, Faculty of Health, \\ Witten/Herdecke University, Witten, \\ Germany
}

*These authors contributed equally to this work

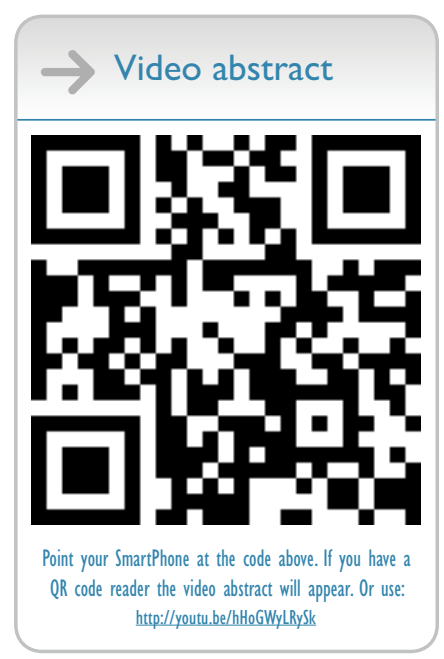

Correspondence: Christoph Nikendei Department for General Internal and Psychosomatic Medicine, University Hospital of Heidelberg, Thibautstraße 2, 69115 Heidelberg, Germany

Tel +49622I 5638663

Fax +496221565749

Email christoph.nikendei@med.uniheidelberg.de
Objectives: This study was designed to explore final-year medical students' stressors and coping strategies at the transition to the clinical workplace.

Methods: In this qualitative study, semi-standardized interviews with eight final-year medical

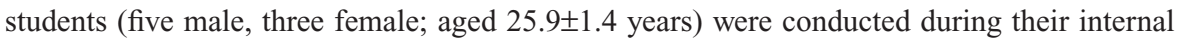
medicine rotation. After verbatim transcription, a qualitative content analysis of students' impressions of stress provoking and easing factors during final-year education was performed.

Results: Students' statements regarding burdens and dealing with stress were classified into four main categories: A) perceived stressors and provoking factors, B) stress-induced consequences, C) personal and external resources for preventing and dealing with stress, and D) final-year students' suggestions for workplace improvement.

Conclusion: Final-year medical students perceived different types of stress during their transition to medical wards, and reported both negative consequences and coping resources concerning perceived stress. As supervision, feedback, and coping strategies played an important role in the students' perception of stress, final-year medical education curricula development should focus on these specifically.

Keywords: undergraduate medical education, stress prevention, final-year medical education, workplace learning, qualitative research

\section{Introduction}

Work process acceleration and increasing workload are important causes for perceived distress among health care workers. Current studies exploring physicians' symptoms of distress show that burnout is more prevalent among physicians and medical students than among comparative samples. ${ }^{1-3}$ Moreover, impacting work performance and patient safety, psychological distress and burnout prevalence rates of $27 \%-75 \%$ among residents are alarming. ${ }^{4}$ Accordingly, a Dutch study revealed that residents report significantly more treatment errors related to actions, judgment, or time pressure when showing burnout symptoms. ${ }^{5}$ These results underline the need for initiatives focusing on the prevention of distress and burnout symptoms, and the consideration of physicians' health. ${ }^{6}$ The fact that young physicians in particular experience high levels of professional burnout in residency training years ${ }^{7}$ pinpoints the need for a focus on prevention of symptoms in medical students to ensure early sensitization and awareness.

Studies have shown that distress and burnout seem to play an important role in the socialization process of medical students. ${ }^{8}$ Correspondingly, medical students showed lower mental health levels compared to reference samples. ${ }^{9}$ Furthermore, mental health 
levels have been shown to decrease, while burnout patterns increase during the course of medical studies. ${ }^{10,11}$ Especially during the final year of medical studies, an alarming $20 \%$ of students were shown to be at risk of burnout. ${ }^{12}$

So far, several models have attempted to improve the understanding of perceived stress burden. ${ }^{13,14}$ Factors contributing to stress experience in physicians-to-be might be found in the gap between students' expectations and the reality of clinical practice. Additionally, knowledge of and strategies for the identification and correction of discrepancies between expectations and actual practice may be lacking. ${ }^{15}$ Although there have been attempts to improve final-year medical students' on-ward integration via introductory weeks, logbooks, fixed consultant-student ratios, the appointment of contact partners, accompanying curricula, and one-on-one teachings at bedside, ${ }^{16,17}$ continuous and sufficient supervision, feedback, and assignment of personal responsibility are still lacking. Moreover, it could be shown that team integration is only minimal, and the occupation with routine activities, eg, blood-taking, is excessive. ${ }^{18}$ Hence, a common effortreward ${ }^{13}$ imbalance model could offer a plausible reason for work-related distress in young physicians. ${ }^{19}$ However, a detailed analysis of perceived stressors at the beginning of students' clinical work during the final year of medical education, and knowledge of medical students' expectations and possible resources at that stage of their training is lacking.

The present qualitative study aimed to elucidate finalyear medical students' specific needs, burdens, and resources during their transition from theoretical, clinical studies to workplace learning demanding independent clinical patient management. Accordingly, final-year medical students' perceptions during their daily work were assessed using a qualitative interview approach, evaluating authentic support possibilities for future final-year medical students. The following research questions were pursued:

1. Which stressors are experienced by final-year medical students during their clinical work?

2. What are final-year medical students' needs within the clinical context and during transition to independent patient management?

3. On what kind of resources can final-year medical students rely during this educational period?

\section{Methods}

\section{Study design and participants}

The aim of the present qualitative study was to reveal students' perceptions of stress inducing and easing factors during final-year medical education, using in-depth analysis of individual interviews. In light of the increasing effect of accelerated work processes on final-year medical education ${ }^{20}$ and the consecutive dissociation between occupational ideals and reality ${ }^{21}$ possibly affecting final-year students' well-being, a qualitative design was chosen to allow participants to express their thoughts and individual perspectives openly. The interviews were conducted with eight final-year medical students during their rotation in the Department of Internal Medicine at the University Hospital of Heidelberg, Germany. The findings of this study will be utilized to establish a specific stress prevention program for final-year students.

\section{Setting and curricular framework}

In the 6th year, the final year in German medical school programs, students are obliged to attend practical on-ward training in a hospital in three areas: internal medicine, surgery, and one elective. The needs assessment was embedded in the final year of medical education at the Medical Hospital of the University of Heidelberg, Germany. The final-year medical curriculum ${ }^{22}$ comprises introductory courses ${ }^{23}$ followed by seminars held 4 days a week (3.30-4.30 pm), including hands-on ultrasound training, weekly electrocardiogram seminars, and courses in clinical pharmacology, as well as skills-lab training, critical care management, advanced life support, and ward rounds. ${ }^{24}$ Additionally, theoretical and practical learning processes are supported by logbooks, ${ }^{25} \mathrm{a}$ state examination training course, ${ }^{26}$ and an on-ward supervision program. ${ }^{27}$

\section{Development of interview questions}

Interview questions were developed based on a literature review as well as an expert team discussion ( $n=3$; one consultant, one physician, one final-year medical student). Siegrist's Effort-Reward model, ${ }^{13}$ which implies that lacking reciprocity of effort and reward can negatively impact affect and well-being, and Karasek's Demand-Control model ${ }^{14}$ served as conceptual framework. In the latter model, a combination of low work-related decision latitude and high work demands is seen to provoke stress. Constructed in a semi-standardized manner, the interview manual contained open-ended, leading questions, followed by encouraging and clarifying questions, if required..$^{28}$ The leading questions were:

1. Which stressors do you perceive as burdensome during your work in the hospital?

2. Which positive stressors do you perceive?

3. What consequences do you experience because of these burdens? 
4. How do you deal with challenging situations and events?

5. How do you avoid getting into stressful situations?

6. How do you deal with stressful situations in the hospital and at home?

\section{Data collection}

During their rotation in the Department of Internal Medicine at the Medical Hospital of the University of Heidelberg, Germany, all of the eleven final-year medical students were informed about the needs assessment. Feedback from eight final-year medical students was obtained. Subsequently, interview appointments with these students were arranged in the following 2 weeks. During the appointments, participants completed questionnaires on basic sociodemographic information, and provided written consent. Individual face-to-face interviews were conducted by a qualified research assistant following the semi-standardized interview manual. After having observed interindividual data content saturation during analysis, further participant recruitment was not pursued. The study was conducted in accordance to the Declaration of Helsinki and approved by the ethics committee of the University of Heidelberg, decision number S-337/2014.

\section{Qualitative analysis}

Conducted interviews were voice recorded, transcribed verbatim, and analyzed following the principles of inductive content analysis. ${ }^{29}$ Firstly, line-by-line, open coding of all interview transcriptions was conducted, where a single or a few sentences were identified as a code, representing the most elemental unit of meaning, as previously defined by Strauss et al. ${ }^{30}$ Next, codes were summarized into relevant themes for each participant, using the software MAXQDA (2011 version, VERBI GmbH, Berlin, Germany). Two independent analysts (authors TRM and CN) assigned codes to specific themes, and subsequently discussed and adjusted respective themes and code assignments to reach a consensus. Accordingly, the resulting theme framework was systematically applied to code and assign all free text quotations, and the analysis was checked for relevance and consistency.

\section{Results}

\section{Participants}

Three female and five male final-year medical students $(n=8$; mean age: 25.9 years; standard deviation: 1.4 ), with a mean study duration of 6.1 years (standard deviation: 0.3 ), participated in the interviews, lasting $33.4 \pm 8.8$ minutes on average.

\section{Main categories resulting from the qualitative analysis}

In the qualitative interview transcripts, 244 single codes matching the research topic were identified and classified into four main categories: A) perceived stressors and provoking factors, B) stress-induced consequences, C) personal and external resources for the prevention and dealing with stress and D) final-year students' suggestions for workplace improvement. Each main category contains up to eight themes (eg, A1-A8). In the following sections, main categories and themes are defined. Exemplary quotations are provided in Figures 1 to 4.

\section{Category A: perceived stressors and provoking factors} Theme Al: stress resulting from routine activities

Final-year students often perceived entrusted clinical activities as unchallenging and therefore burdensome. Describing them as "runaround" or "auxiliary tasks", students regarded drawing blood samples, placing indwelling venous catheters, and taking electrocardiograms as delegated, time-consuming, routine activities which were unsatisfactory, lacking in responsibility, and stressful. In addition, taking patients' history and performing physical examinations during admission procedures were also partly seen as tasks with little learning benefit when lacking supervision. Moreover, routine activities were also seen to encumber the acquisition of professional competencies, as capacities for more instructive situations, such as taking part in ward rounds, were lacking. Creating capacities for more complex activities, resident physicians' personal workload reduction was largely seen as the motive behind the entrustment of aforementioned clinical tasks to final-year students. Accordingly, some students perceived themselves as "cheap manpower".

\section{Theme A2: lack of skills and knowledge}

Aside from overburden with routine activities, final-year students described lacking experience in the management of other entrusted, non-routine clinical tasks, as causing additional feelings of burden and dissatisfaction. For example, some assigned activities at bedside, such as handling central venous catheters or working under sterile conditions, were perceived to be as stressful as procedures that had not been observed or performed before.

\section{Theme A3: timing/organizational issues}

Final-year students perceived timing and organizational factors as stressors. Working overtime, time pressure, high task numbers, and required multitasking, as well as 
uncoordinated workflow, were seen as stressful (eg, receiving inpatient calls for diagnostic and invasive procedures during patient history-taking or admittance). In contrast, recurring long periods of idle time were also seen as burdensome.

Theme A4: final-year students' role conflicts

Final-year students experienced role conflicts as a source of stress, perceiving difficulties in the delegation or the assignment of tasks to nursing staff. Moreover, areas of responsibilty between nursing staff and final-year students for certain activities, such as drawing blood samples, were sometimes unclear.

Theme A5: communicative difficulties with staff and patients Difficulties in communication with staff and patients were perceived. Final-year students regarded the tone of

\section{A1: stress resulting from routine activities}

- "The activities are just, are just like ancillary activities, as in drawing blood, placing needles, recording ECGs ... and taking a quick patient history, but very little independent work really. [...] So, not really stressful, but more just repetitive, really, and just a little unsatisfactory, frankly." (T1)

- "... work overload occurs or stress really sets in partly because of this mindless routine and the, eh missing ehm, lack of responsibility, exactly, good term: lack of responsibility, lack of ehm, lack of status as a medical team member, being treated more like a student ..." (T4)

- “... we never talked about what we actually expected of it or what our responsibilities were and uh, so actually, we were a little like the ward's errand boys. One has to, one has to say and ehm ... Yes, it was, I think, it was never intended differently, I think, yes, it did feel a little like being an errand boy." (T6)

\section{A2: lack of skills and knowledge}

- "Yes, from time to time, just that you're there with the patient and aren't exactly sure, because you've just not seen it done before, perhaps [...] when giving a patient information, where you thought: "you've already done this" and are familiar with it and then you realise at bedside that you haven't seen this task before, done it before, and that does get quite stressful." (T2)

- "It gets stressful for me when l'm supposed to do something, anyway, or get some instructions, I'm with the patient and perhaps haven't seen or done the procedure quite as often previously, well, really, situations, where one goes in feeling unprepared." (T2)

- "When l've got the impression that because of stress or, or because I lack knowledge in the field, anyway, of course, I feel kind of unsatisfied. Yes, then it's a bit like "okay, bummer, but you should've known this" or "hugh, that didn't go well"." (T7)

\section{A3: timing/organizational issues}

- "That somehow patients, ehm, were fetched far earlier than would be the case normally." (T3)

- "It's, what annoys me a little is that everything is often very uncoordinated. So, if you, like, if you go round in the morning, to draw blood for instance, that you practically have to go around again because some sample tubes were forgotten to be set up, well, of course, that's really unnecessary work, which simply somehow, subconsciously, well, so, is just kind of, maybe actually produces stress." (T5)

- "Er, it's often the case, unfortunately, that we aren't able to make the ward rounds here because just somehow several things always come together at the same time everywhere else or always in between things, so we only get to see a couple of patients, then we'll do something else again, then we join the rounds again." (T5)

\section{A4: final-year students' role conflicts}

- "It stresses me out if I don't know who I should tell these things and then if I've reported it and I know "it's sorted", then is not so stressful anymore. So, it is realy like, um, yes, there is always something unfinished at the back of your mind because you don't know who to report to or you can't do it yourself because you don't have to the opportunity to do it and it's like ... a bit unsatisfactory often." (T6)

- "... one thing is difficult, namely, as soon as you start your final-year internship, although you're not a medical doctor yet, to give ehm instructions or advice." (T7)

- "The problem is only that sometimes, when you just come into a room, it's often unclear whether you're somehow a nurse or a physician. So, I think that's not really clear at first glance for, for many patients somehow [...] with that, the responsibility is not quite as clear, it makes communication difficult, of course." (T5)

Figure I (Continued) 


\section{A5: communicative difficulties}

- "... strict hierarchy exists between the different professions, and therefore, there is just a shortage, a lack of communication, that's most decisive, among other things." (T2)

- "Well, simply that communication with senior physicians and heads is like, ehm, is just non, ehm, existant. Well, of course, you could talk to them or something, ehm, but there just somehow, like, no real reason for it, anyway, and they're usually also not really interested in you as a final-year student." (T3)

- "... the harsh tone, short brusque answers, little personal communication and welcoming on the first day, and ehm .. lack of interest." (T4)

\section{A6: difficulties in learning}

- "But it is not like, at least on-ward, the focus is not really on you learning something." (T1)

- "Well, the learning curve, so to speak, anyway, let's say, depends on your own initiative to about 80 to 90 percent. In other words, if you don't have it, then you only have 10 to 20 percent benefit. And even, even if you'd show the maximum, the maximum initiative, you'd never reach 100 percent. Simply doesn't work." (T4)

- "Learning on-ward, l'd have to say, well, this is my first deployment here, and I wasn't able to gain that much from it. Firstly, because it is relatively specific and secondly, because you also, aside from, aside from the usual work on-ward, which you do here and aside from the routine, it's not like you really are able to catch much more. Well, it's not like very much is explained here, if you don't explicitly ask, ehm, you don't really benefit." (T5)

\section{A7: Difficulties in team integration}

- "You aren't really integrated, that's the problem, I think, because you don't feel part of the team." (T2)

- "Everyone is, well like, a little bit overloaded working as residents and ehm, then they don't really see why they should be doing someone elses' work, when they've just managed to have a little breather." (T3)

- 'From a final-year students' perspective, you're a student, but are also being treated like a student. So, ehm, ehm, from, so you, you, you just realize that you're actually the odd man out, and essentially, can only be really used productively for, like, menial activities." (T4)

\section{A8: psychological stress provoking factors}

- 'Yeah, well, if you're, like, somehow tired or are generally feeling under the weather then, of course, it's also a factor that can trigger stress. But that's not really often the case with me. But, for example, especially, when you've had too little sleep, then it's a factor. When you're, like, tired in the morning already, or something." (T1)

- "Another aspect is that due to this fact, ehm, well, well, l'd say there're idle times, you know. Well, when you can't really do anything that's productive, for me these periods, where you're left hanging around idly, to that respect in fact, are almost, anyway, the most stressful situations." (T4)

- "When a patient decompensates, for example, well, you know, like, when the patient is just doing really badly and your own adrenaline rises." (T7)

Figure I Exemplary quotations for main category A): perceived stressors and provoking factors.

Note: $(\mathrm{T} \#)$ denotes participant code.

communication among health care professionals as harsh and short-spoken, and saw rigid working structures as further communicative stressors. Patient-student communication was sometimes seen as complicated or inadequate. Thereby, insufficient communication between resident physicians and students was often reported to produce difficult student-patient interactions, eg, the inability to answer patients' questions regarding procedures, such as drawing blood or administering intravenous chemotherapy. In addition, increased stress on-ward resulted in minimized 


\section{B1: personal consequences}

- "Difficult, well I, l'm more, more, like, maybe a little bit angry." (T5)

- "I mean, the shifts we're working are 16.5 hours at a time, which is, of course, pretty stressful, so you really notice it in the evening that your ability to concentrate really, really suffers." (T6)

- "I notice, for example, that my lips start trembling, that I begin to get a little tachycardic, yeah, I do, exactly, obviously and that I become sweaty ... cold sweat .. and that the hands are particularly sweaty, you know. Typical stress reaction, I think." (T7)

\section{B2: consequences for professional conduct and attitude}

- "I can also see that with myself, when I get stressed, that I just, that I simply don't work as well as when its calm." (T5)

- "Well, like, some degree of dulling somehow goes along with the profession perhaps, so, a little bit like that you try maintaining some distance, more distance to the patient." (T2)

- “... that l'm not able to work as well, l'am in a bad mood when interacting with people." (T1)

Figure 2 Exemplary quotations for main category B): stress-induced consequences. Note: (T\#) denotes participant code.

communication efforts, while frequent rotations within the team were also seen to increase the risk of information loss. Further communicative difficulties resulted from hierarchical or role structures, with students feeling disregarded by resident physicians and nurses feeling offended by students' attempts to delegate tasks.

\section{Theme A6: difficulties in learning}

Final-year students reported only marginally successful and sometimes discouraging learning experiences. Resident physicians' lack of motivation to teach students clinical knowledge, especially expert clinical reasoning not found in medical textbooks, was criticized. Moreover, students felt alongside learning to be restricted as, for example, they rarely had the time to accompany physicians on ward rounds due to many routine tasks. Some saw insufficient team integration as a potential source for the lack of valuable learning experiences (see section "A7: Difficulties in team integration"). Students regarded the acquisition of knowledge, skills, and professional behavior to be chiefly limited to the accompanying final-year curriculum. Furthermore, students assumed peripheral teaching hospitals to have more resources for the promotion of bedside teaching than university clinics.

\section{Theme A7: difficulties in team integration}

Therapeutic team integration was seen to be poor, with students often feeling more like short-term "temps" than full-fledged team members. Missing debriefings after admission procedures (eg, history-taking), little tolerance of work delay despite high workload, as well as time pressure and few possibilities to participate in ward rounds (see section "A1: Stress resulting from routine activities"), were perceived as indicators for lacking team integration. Students saw their "special status" (entailing a minimum of 60 minutes daily ward absence while attending finalyear curriculum courses) as a reason for their poor team integration. Moreover, their feeling of lack of scope for action compared to fully qualified physicians was reaffirmed by the fact that students are generally not permitted to administer medical orders.

\section{Theme A8: psychological stressors}

Final-year students named stress provoking or intensifying psychological factors. Personal factors, such as tiredness or lack of self-confidence, were reported. However, patientrelated stressors, such as the patients' dissatisfaction, tragic fate, or cardiovascular decompensation, were predominant.

\section{Category B: stress-induced consequences}

Theme BI: personal consequences

Final-year students discussed consequences resulting from experienced stress, naming physical and psychological symptoms, such as shivering, sweating, as well as reduced enthusiasm for work, emotional retreat, anger, and loss of concentration.

Theme B2: consequences for professional conduct and attitude

Stress affected students' professionalism in terms of their capacity to communicate adequately as well as their 


\section{C1: Communicative resources}

- "Well really, I'm not that easily perturbed, so ... I uh ... If something bothers me, I usually address it." (T1)

- "Yes, like, quite frankly, quite obviously. In the first three days, l'd like have a little chat with the nurses, just friendly like, and treated them as, ehm, competent, uhm, employees first of all, ehm, treated them normally, like how you should actually do it and consequently the tone did indeed suddenly change toward me, you know." (T4)

- "Er, I usually talk a lot about it with people, well, no names said that is, or anything, but I elaborate, well, I talk about things quite a lot when they really bother me. Like, also with friends, family ... talking, yes." (T6)

\section{C2: behavioral resources}

- "Resources, I would take a break, for example, like, l'd take one anyway. Despite a lot of work. And ... um, yes, otherwise, l'd just try to get the job done as quickly as possible in a structured manner, yes." (T1)

- "Yes, taking a walk, just a little bit anyway, strolling, somehow poking an eye at what's happening, like, in the world." (T3)

- "Well, like, a healthy degree of initiative in places where the, the probability of success is relatively high or the potential benefit is simply enormous." (T4)

\section{C3: reflective-evaluative resources}

- "Being productive. Analysing. Ehm, are the most important. To get your head round things first, then analyse and then change, ehm, things. Well, I'm a very active person. So, I do not bottle things up, but will in doubt, take action ... like." (T4)

- "Well, the most important thing is that you know exactly that a stressful situation is going to occur and that you also know exactly why it's a stressful situation and that you premeditate actions or at the latest when the situation arises, and start thinking "what can I do about this"." (T4)

- "I think, uh, that problems, challenges, obstacles, whatever you want to call it, can really only be mastered, if you actively approach them. But in some cases, you also have to consider whether overcoming the hurdle or obstacle is at all worthwhile" (T4)

\section{C4: external resources}

- "If I was overwhelmed by a situation, l'd get a senior colleague, ask when I don't know something, would say that l'm not able to do something, in advance, that is, before the milk has been spilt, l'd say." (T2)

- "If you're just not able to do it, ask someone or get help and simply don't be too proud, ehm, to let someone else do it, ehm, because you couldn't do it, so really, just ask again and again and someone else, so you can go home with a good feeling." (T6)

- "Well, at home, obviously, a good social environment, definitely. Well, simply, just regular fixed dates to go to, as in having a secure environment." (T6)

Figure 3 Exemplary quotations for main category C): personal and external resources for the prevention and dealing with stress. Note: $(\mathrm{T} \#)$ denotes participant code.

performance of patient-related activities. Examples, such as snarling at colleagues, and forgetting to administer intravenous fluids, were given.

\section{Category C: personal and external resources for dealing with, and the prevention of stress}

Theme $\mathrm{Cl}$ : communicative resources

Students provided feedback on the communicative resources, such as seeking social support and actively addressing problems, especially with their family, friends, and colleagues. Accordingly, communication difficulties with nursing staff could be resolved or improved.

\section{Theme C2: behavioral resources}

Various proactive resources for acute stress situations, such as taking a break or "relaxing emotionally" to achieve inner distancing from stressful situations, as well as seeking support, were reported. In addition, students named keeping a 


\section{D1: technical aspects}

- "In the very first rotation, you don't know what you're gonna start withif you're gonna start with your elective subject or internal medicine; [it would be helpful] that you'd be able to perhaps refresh your knowledge on the basics that one might encounter in everyday life or maybe somehow, something like a course with basic information on how to use the clinic's software."

- "Well, from friends, who did their final-year internship in Switzerland, l've heard, ehm, that there everything was done electronically, when someone gives a medical order, then everyone can see it on all devices, which might help avoid some mistakes, that you simply say: everyone is able to access far more information that is relevant, but that's, of course, a problem in the system. That would be difficult to get rid off here." (T2)

- 'Well, it would make sense if every final-year student could have a phone, because we're two at the moment [on the ward] and we only have one between us." (T2)

\section{D2: learning and teaching aspects}

- "I am convinced [...] of the fact that it's necessary, ehm, that patients are really actually assigned to you, for example, well, that's always what one imagines, ehm, that, that a student is assigned to a patient room. A room, with two patients in it, who he simply must look after, under the supervision of the resident physician. I think, that, that would be like the ideal. To be supervised by an assistant and a senior physician." (T7)

- "It would be good perhaps, for like everyday procedures, that you would have, like, a skills-lab [Skills training program] on it, uh, no idea, to practice central venous catheters again, cannulation, how to work in a sterile manner, how the used systems work, the most common ones on-ward, what's important in regard to dosages, iv administration, im administration, things like that, that you have a closer look at them in respect to the specific ward." (T2)

\section{D3: Communicative aspects}

- "I'd also invite other individual disciplines, like surgery and internal medicine, that they could also improve communication between each other, better coordination and perhaps even mutual appreciation, of course, that also goes for physician and nurses." (T2)

- "Yes, maybe in the morning, if you were able to very briefly have an update with the physician,"this 'n'this 'n'that 'n'that, is there anything specific?"; that one goes through all the patients once briefly, either with the nurse, or with the physician, simply to get the specifics." (T6)

- "Of course, I can also go and ask, "this 'n'that, anything specific?" Um ... Don't do that, yeah, I simply ask the patient beforehand mostly, who, usually, have a good idea of most of the stuff. I just somehow try to ask the patient. Ehm, yes. Somehow obtain information from the patient." (T6)

Figure 4 Exemplary quotations for main category D): suggestions for improvement. Note: (T\#) denotes participant code.

well-organized life (sufficient sleep, regular nutrition, a daily routine, and regular periods of relaxation), being physically active (taking walks, sports), keeping a professional distance when dealing with emotional burden, and avoiding patients' difficult questions (eg, regarding life expectancy) as behavioral resources. Futhermore, proactively seeking encouragement, such as engaging in gratifying conversations with patients after experiencing work-related failure or difficulties (eg, conflicts with colleagues), was also reported as beneficial.
Theme C3: reflective-evaluative resources

Students named reflective--evaluative resources, such as confidence in their own coping and problem-solving capacities, as beneficial. In addition, the anticipation of burden allowed students to take suitable countermeasures, such as workflow adjustment or breaks, and guarded them against the negative impact of daily hassles. Furthermore, reflecting and reframing difficult situations was seen as beneficial, and keeping personal effort and reward balanced was seen as important. Hence, the prospect of receiving satisfactory clinical teaching 
led to a less burdensome perception of clinical work, and increased students' initiative. By contrast, students' initiative decreased if they felt insufficiently trained. Additionally, perceived to be inadequately low in relation to their workload, students' pay dissatisfaction (German final-year medical students receive a monthly wage of up to $597 €$ ) was also reported to negatively impact motivation. In contrast, the final-year medical students" "special status," omitting them from fully qualified physicians' responsibilities and burdens, was seen as a stress alleviating factor. Accordingly, efforts to keep a realistic and appreciative view of their competencies and the development of positive self-perception were seen as protective factors in burdensome, high workload periods. Moreover, students perceived self-reflective competencies to guard them from increasingly negative thoughts, such as self-doubt, as promoting noxious stress effects.

\section{Theme C4: external resources}

Students reported committed physicians, a stable social network, and good team integration as positive external resources. Generally, the relationships with physicians and nursing staff were reported to be good. Moreover, experiences of being appreciated and taken seriously, receiving team support during high workload periods, as well as being entrusted with independent tasks, were perceived as beneficial. Although the extent of team integration was seen as being largely dependent on the students' own behavior and effort, physicians' training capacities were also believed to be a moderating factor. Accordingly, the experience of successful final-year training was greatly improved, for example, by the possibility of asking questions and receiving explanations during ward rounds. Ward rounds were considered as good opportunities to connect with other team members, though physicians often only provided explanations upon students' explicit requests. In addition, the possibility to engage in further literature study during idle time was seen as beneficial. Potential stressors, resources, and consequences resulting from unbalanced stress are summarized in Figure 1.

\section{Category D: suggestions for improvement}

Theme DI: suggestions related to technical aspects

Final-year students stated that a computer-based system providing more elaborate medical information on patients, as well as the possibility to follow all medical orders from various computers or electronic devices instead of only recording them in patients' files, would improve communication and counteract information loss. Furthermore, the adequate provision of workplace technology, such as equipping every final-year student with a portable hospital phone, would greatly facilitate internal arrangements, such as the coordination and delegation of tasks, or information exchange.

\section{Theme D2: suggestions related to learning and teaching}

In an effort to broaden the students' knowledge of diseases, more frequent rotations to other wards were suggested. Additionally, the establishment of further planned, physician-led, on-ward teaching elements, the assured participation in ward rounds, and increased supervision by senior physicians were seen as important suggestions for improvement. Furthermore, it was suggested that on-ward teaching could be improved by offering physicians additional teaching incentives (eg, teaching could reduce physicians' workload as more activities could be entrusted to students). Furthermore, for reducing stress burden, students saw the establishment of revision or refresher courses, as well as the provision of specific skillslab to practice ward-related activities (eg, the handling of central vein catheters), as highly beneficial for their final-year on-ward deployment.

\section{Theme D3: suggestions related to communicative aspects} Suggestions for the improvement of medical staff communication included the establishment of clear working structures and agreements within the team. Furthermore, specific team-related, interprofessional (eg, between nursing staff, physicians, surgeons, and internists), as well as patient-centered communication trainings, were seen as potential sources for improvement. Students perceived communicative training to simultaneously build up coping resources, ease workflow coordination, promote team cohesion, and alleviate stress burden.

\section{Discussion}

The presented study was designed to investigate final-year medical students' perceived stressors, resources, and needs during their transition from theoretical, clinical studies to workplace learning. As this is an important developmental step toward medical professionalism, the focus was set on students' daily clinical work during final-year medical education. Our study revealed severe stressors that, according to current models, could cause the development of chronic stress symptoms and hinder the achievement of medical professionalism. Identified stressors led to striking intra- and interpersonal constraints, affecting self-efficacy, teamwork, and patient treatment, partly counterbalanced by final-year students' personal and external resources. Furthermore, suggestions regarding stress-reducing measures during final-year medical education were identified. 
Regarding final-year medical education stressors, it was discovered that the perceived lack of competencies in clinical skills led to uncertainties in final-year students' clinical performance at bedside, promoting stress burden. Moreover, the exorbitant number of assigned routine activities were perceived to contravene the development of medical competencies as provided by the CanMEDS educational framework. ${ }^{31}$ This is in line with a previous qualitative study assessing final-year medical students' expectations prior and post clinical assignment, ${ }^{18}$ which revealed that students expected to "improve clinical skills" and "take responsibility for patient care" in the "presence of supervisors" prior to their clinical rotation, but experienced "a misuse of their compentencies for routine activities", "excessive/undefined working times", "lack of supervision", "unmotivated supervisors", and a "negative working atmosphere".

In the current study, observed "extreme effort conditions" combined with "low reward," such as unsatisfying supervision, feedback, and on-ward teaching, possibly led to imbalanced high effort/low reward perceptions. According to Siegrist's Effort-Reward model, ${ }^{13}$ these perceptions might be reinforced by the lack of clinical skills and, consequently, may result in a potentiation of psychological burden. Previous research has revealed that lack of guidance during clinical rotations is a significant source of fear and anxiety for students. ${ }^{32}$

Final-year medical students have also reported stress due to difficult timing and organizational issues, such as the interruption of history-taking by inpatient calls (eg, X-ray and ultrasound appointments), and communicational issues, such as the omission of information, (ie, the indications for medical procedures). This is in line with the frequently cited Demand-Control model, ${ }^{14}$ which demonstrates that high job demands accompanied by low control lead to high strain, possibly decreasing final-year students' motivation, and may result in feelings of resignation, as described by Karasek. ${ }^{14}$ This is noteworthy, as self-motivation is described as a crucial factor for successful studies. ${ }^{33}$ Although there are no data describing the effectiveness in clinical settings, first initiatives have begun to address strategies to structure students' clinical work by delivering time management techniques. ${ }^{34}$ The accompanying curriculum was shown to be effective in empowering final-year students' clinical skills and knowledge, but it requires students' daily ward absence. Therefore it was partly held responsible for poor team integration and could, in turn, lead to the decreased entrustment of final-year medical students, resulting in a vicious cycle. To break this cycle, it is suggested that awareness among resident physicians for the content and the importance of the accompanying curriculum should be improved, thus achieving more acceptance for students' absences. In addition, more attention should be directed toward other measures to enhance students' team integration, such as longer periods of deployment on the same ward, regular, scheduled feedback, and supervision at the beginning, during, and at the end of rotations, prompting the development of responsibility, the reduction of routine tasks, and the implementation of logbooks as a tool to keep track of individual learning progress. Furthermore, the appointment of an "external", non-ward-related contact person for finalyear medical students could foster the students' feeling of a supportive working environment and prove to be valuable in the mitigation of work-related conflicts.

Final-year students also reported dysfunctional team communication, including personal devaluation by team members, especially from more senior members (eg, attending physicians), and communicational deficits, such as harsh and short-spoken interactions or disregard. Cook et $\mathrm{al}^{35}$ recently reported that "recurrent mistreatment by faculty and residents is associated with medical student burnout". Moreover, students' perceived role conflicts, such as difficulties in the delegation of tasks to nursing staff, and poor team integration, highlight the importance of team communication and conflict management trainings shown to be effective in previous studies. ${ }^{36}$

Described stressors have been shown to lead to negative effects on final-year medical students' self-perception and clinical performance. In line with recent literature showing the negative association between symptoms of burnout and productivity ${ }^{37}$ interviewed students reported physical, psychological, and quality of work-related, stress-induced consequences.

However, final-year medical students also built on a variety of resources, facilitating the handling of daily hassles. A sufficient social network, social support, stress relieving behavior, and self-reflective competencies were named. Additionally, medical students mentioned keeping a professional distance as a coping strategy, emotionally safeguarding them they were involved in the treatment of patients with a tragic fate. However, strong emotional distancing may promote the development of cynicism or loss of medical core values, ${ }^{38}$ reaffirming medical students' need for mechanisms of self-care and well-being. ${ }^{39}$ Accordingly, the success of systematic stress prevention program ${ }^{40}$ and facilitation of mindfulness training $^{41,42}$ have recently been shown to be effective.

Several suggestions on improving the stressful clinical surroundings, such as computer-based support to avoid information loss, and facilitation of interprofessional 
communication, were made. Accordingly, the need for the further development of interprofessional and patient-oriented communicative trainings that have been proven to be relatively effective (eg, in regard to patient safety ${ }^{43}$ or student empathy ${ }^{44}$ ), despite difficulties in implementation and longterm effectiveness, ${ }^{45}$ was voiced.

Above all, the aforementioned stressors and consequences should be considered as a call for action, as several arguments for curricular changes can be derived from the findings of the current study. As the interviewed final-year medical students perceived on-ward teaching as an important resource to improve their knowledge, team integration, and enthusiasm for work, these should serve as linchpins for curricular changes. Implemented guidance, supervised on-ward teaching, ${ }^{27,46}$ personal assumption of clinical responsibilities, ${ }^{47}$ and the training of relevant clinical skills prior the start of the final year ${ }^{23,48}$ have been previously shown to be essential parts in final-year medical education. However, effective team communication and conflict management trainings $s^{36}$ could additionally empower students to deal with conflict. Nevertheless, respective trainings are still underrepresented in medical education curricula, ${ }^{45}$ although the findings of the current study suggest that even rudimentary courses might have been helpful to the participants in regards to team integration. Providing future physicians with further protective measures to deal with psychological impairment which could limit productivity or induce job-related burnout; for example supportive offers of teaching, and reinforcing successful stress-related coping strategies, such as mindfulness-based stress reduction (MBSR), ${ }^{49}$ should also be implemented in basic medical curricula. However, bearing in mind the law of inverse care ${ }^{50}$ ("availability of good medical care tends to vary inversely with the need for it in the population served"), it must be noted that students with potentially higher needs for stress prevention are more difficult to reach, highlighting the substantial responsibility of physicians and faculty members when it comes to supporting final-year students' learning, team integration, and the gratification they feel for their efforts.

\section{Limitations}

Certain limitations of this study should be noted. Firstly, this study is limited by the number of participants due to the qualitative method used, which included in-depth interviews

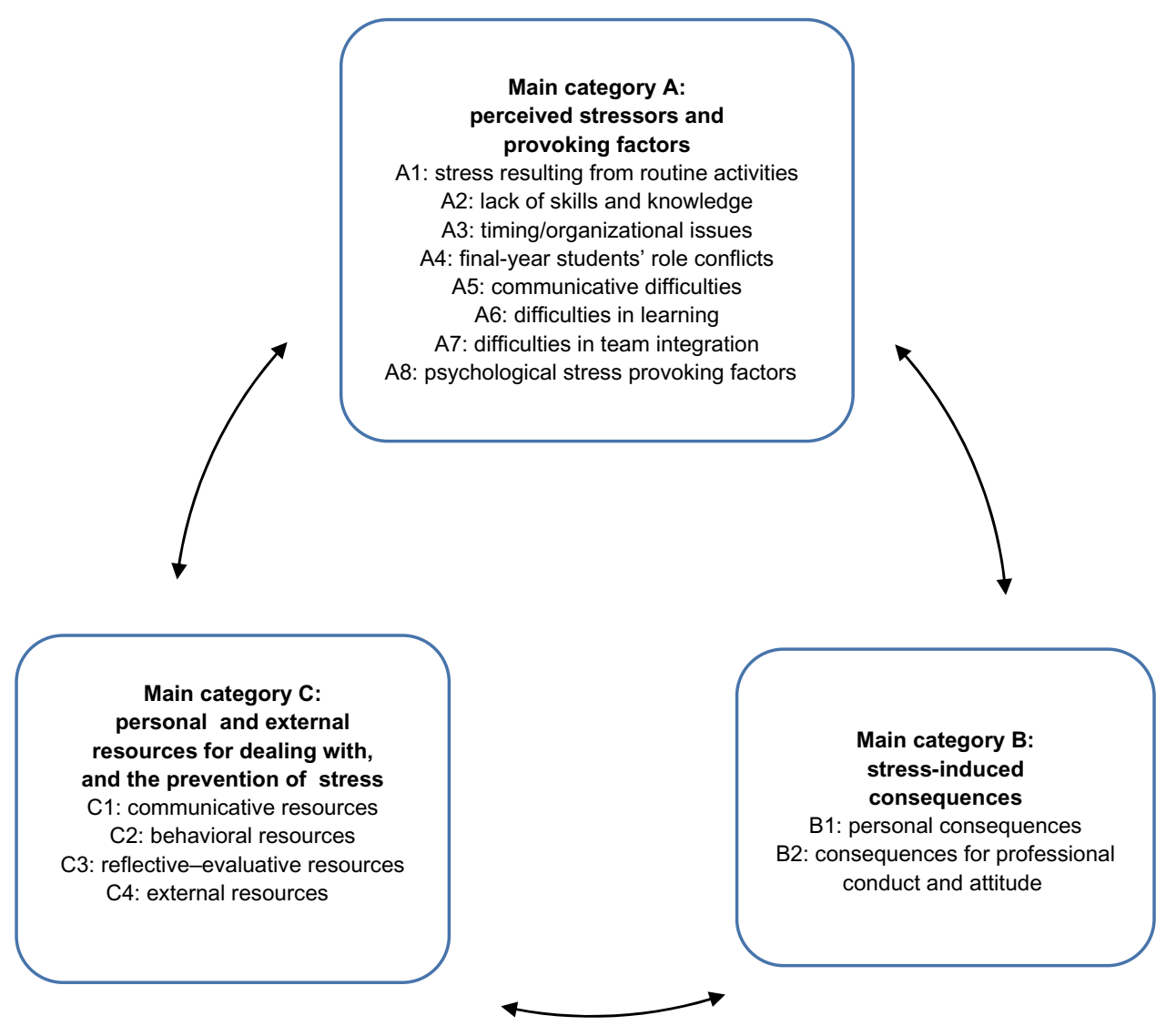

Figure 5 Flowchart showing potential stressors, resources, and consequences resulting from unbalanced stress. 
and analysis. Moreover, participation was voluntary, possibly leading to bias in the analysis. Furthermore, although the qualitative content analysis was performed according to inductive category development, and was verified by a second analyst, the study could be considered as more subjective than quantitative, and therefore, results are not generalizable and transferable to all medical students and medical schools. Finally, the flowchart (Figure 5) showing stressors, resources, and consequences resulting from unbalanced stress is only proof-of-concept and requires further quantitative validation. However, due to its openness in terms of assessment technique and the use of detailed interviews and quotations, the analysis enabled a more complete picture of this multilayered area of research, and led to a number of new aspects omitted from previous studies. The results of the current study could be used as a first step toward the improved understanding of final-year medical students' needs during their transition to workplace learning, and should therefore serve as a basis for further qualitative and quantitative studies.

\section{Conclusion}

As supervision, feedback, and coping strategies played an important role in the students' perception of stress, there is a strong argument for the continuous development of finalyear medical curricula under the emphasis of the following aspects: 1) the intensive guidance of medical students (including the defined provision of supervision, feedback, and theoretical, as well as practical, on-ward bedside teaching by physicians) to prevent unbalanced high effort/low reward conditions, gratification crises, and the potentiation of psychic burdens and impairment; and 2) the implementation of stress reduction programs for final-year medical students (repeatedly described as beneficial for students' well-being) (0 $^{40}$ to create a constructive and healthy work culture for finalyear medical studies and future physicians' workplaces, consequently ensuring future optimal patient care.

\section{Acknowledgments}

This study was supported by the Baden-Württemberg Stiftung as part of the program "Fellowships für Innovationen in der Hochschullehre". This program was signed jointly by the Stifterverband für die Deutsche Wissenschaft and the Baden-Württemberg Stiftung. We acknowledge the financial support of the Deutsche Forschungsgemeinschaft and Ruprecht-Karls-Universität Heidelberg within the funding program Open Access Publishing. The authors would like to thank the participating students and Anna Cranz for translating the German quotations into the English language and proofreading the manuscript.

\section{Author contributions}

All authors contributed toward data analysis, drafting and revising the paper and agree to be accountable for all aspects of the work.

\section{Disclosure}

The authors declare that they have no competing interests.

\section{References}

1. Dyrbye LN, West CP, Satele D, et al. Burnout among US medical students, residents, and early career physicians relative to the general US population. Acad Med. 2014;89(3):443-451.

2. Walkiewicz M, Sowińska K, Tartas M. [Burnout in medical profession - a literature review]. Przegl Lek. 2014;71(5):263-269. Polish.

3. Romani M, Ashkar K. Burnout among physicians. Libyan J Med. 2014;9.

4. Ishak WW, Lederer $\mathrm{S}$, Mandili $\mathrm{C}$, et al. Burnout during residency training: a literature review. J Grad Med Educ. 2009;1(2):236-242.

5. Prins JT, van der Heijden FM, Hoekstra-Weebers JE, et al. Burnout, engagement and resident physicians' self-reported errors. Psychol Health Med. 2009;14(6):654-666.

6. Wallace JE, Lemaire JB, Ghali WA. Physician wellness: a missing quality indicator. Lancet. 2009;374(9702):1714-1721.

7. Thomas MR, Dyrbye LN, Huntington JL, et al. How do distress and well-being relate to medical student empathy? A multicenter study. J Gen Intern Med. 2007;22(2):177-183.

8. Dyrbye LN, Thomas MR, Shanafelt TD. Medical student distress: causes, consequences, and proposed solutions. Mayo Clin Proc. 2005; 80(12):1613-1622.

9. Helmers KF, Danoff D, Steinert Y, Leyton M, Young SN. Stress and depressed mood in medical students, law students, and graduate students at McGill University. Acad Med. 1997;72(8):708-714.

10. Voltmer E, Rosta J, Aasland OG, Spahn C. Study-related health and behavior patterns of medical students: a longitudinal study. Med Teach. 2010;32(10):e422-e428.

11. Scholz M, Neumann C, Steinmann C, et al. [Development and correlation of work-related behavior and experience patterns, burnout and quality of life in medical students from their freshmanship to the first state examination]. Psychother Psychosom Med Psychol. 2015; 65(3-4):93-98. German.

12. Koehl-Hackert N, Schultz JH, Nikendei C, et al. [Burdened into the job - final-year students' empathy and burnout]. Z Evid Fortbild Qual Gesundhwes. 2012;106(2):116-124. German [with English Abstract].

13. Siegrist J. Adverse health effects of high-effort/low-reward conditions. J Occup Health Psychol. 1996;1(1):27-41.

14. Karasek RA. Job demands, job decision latitude, and mental strain. Implications for job redesign. Adm Sci Q. 1979;24(2):285-308.

15. Benbassat J, Baumal R, Chan S, Nirel N. Sources of distress during medical training and clinical practice: Suggestions for reducing their impact. Med Teach. 2011;33(6):486-490.

16. Raes $P$, Angstwurm M, Berberat $P$, et al. Quality management of clinicalpractical instruction for practical year medical students in Germany proposal for a catalogue of criteria from the German Society of Medical Education. GMS Z Med Ausbild. 2014;31(4):Doc49.

17. Nikendei C, Krautter M, Celebi N, Obertacke U, Junger J. Final year medical education in Germany. Z Evid Fortbild Qual Gesundhwes. 2012;106(2):75-84. 
18. Schrauth M, Weyrich P, Kraus B, Jünger J, Zipfel S, Nikendei C. [Workplace learning for final-year medical students: a comprehensive analysis of student's expectancies and experiences]. Z Evid Fortbild Qual Gesundhwes. 2009;103(3):169-174. German [with English Abstract].

19. Li J, Weigl M, Glaser J, Petru R, Siegrist J, Angerer P. Changes in psychosocial work environment and depressive symptoms: a prospective study in junior physicians. Am J Ind Med. 2013;56(12):1414-1422.

20. Santen SA, Holt DB, Kemp JD, Hemphill RR. Burnout in medical students: examining the prevalence and associated factors. South Med J. 2010;103(8):758-763.

21. Schrauth M, Kowalski A, Weyrich P, et al. [Self-image, real physician's and ideal physician's image: a comparison of medical students 1981 and 2006]. Psychother Psychosom Med Psychol. 2009;59(12):446-453. German.

22. Nikendei C, Mennin S, Weyrich P, et al. Effects of a supplementary final year curriculum on students' clinical reasoning skills as assessed by key-feature examination. Med Teach. 2009;31(9):e438-e442.

23. Nikendei C, Kraus B, Schrauth M, Weyrich P, Zipfel S, Jünger J. An innovative model for final-year students' skills training course in internal medicine: 'essentials from admission to discharge'. Med Teach. 2006;28(7):648-651.

24. Nikendei C, Kraus B, Lauber H, et al. An innovative model for teaching complex clinical procedures: integration of standardised patients into ward round training for final year students. Med Teach. 2007;29(2-3):246-252.

25. Kraus B, Jünger J, Schrauth M, et al. Logbooks in clinical use - is there a benefit for the students? An Evaluation among final-year-students in internal medicine. GMS Z Med Ausbild. 2007;24(2):Doc112. German [with English Abstract].

26. Krautter M, Jünger J, Koehl-Hackert N, Nagelmann L, Nikendei C. [Evaluation of a structured, longitudinal training program for the preparation for the second state exam (M2) - a quantitative analysis]. $Z$ Evid Fortbild Qual Gesundhwes. 2012;106(2):110-115. German [with English Abstract].

27. Eden M, Köhl-Hackert N, Krautter M, Jünger J, Nikendei C. An innovative model for the structured on-ward supervision of final year students. Med Teach. 2010;32(2):181.

28. Helfferich C. Qualität qualitativer Daten-Manual zur Durchführung qualitativer Einzelinterviews [The quality of qualitative data - a manual for qualitative one-on-one interviews]. Wiesbaden: VS-Verlag; 2005. German.

29. Mayring P. Einführung in die qualitative Sozialforschung. Eine Anleitung zu qualitativem Denken [An introduction to qualitative content analysis. A guide to qualitative thinking]. 5., überarb. und neu ausgestattete Aufl. Beltz Studium. 2002.

30. Strauss AL, Corbin JM, Niewiarra S. Grounded theory: Grundlagen qualitativer sozialforschung [Basics of Qualitative Research]. Beltz, Psychologie-Verlag-Union; 1996. German.

31. CanMEDS. CanMEDS 2005 Framework 2005. Available from http:// www.royalcollege.ca/portal/page/portal/rc/common/documents/canmeds/ framework/the_7_canmeds_roles_e.pdf. Accessed May 23, 2015.

32. Nikendei C, Köhl-Hackert N, Jünger J. Peer-assisted learning: a planning and implementation framework. Guide supplement 30.3 - practical application. Med Teach. 2008;30(4):442-443.
33. Goldie J, Dowie A, Goldie A, Cotton P, Morrison J. What makes a good clinical student and teacher? An exploratory study. BMC Med Educ. 2015;15(1):314.

34. Kraus B, Briem S, Jünger J, et al. Entwicklung und evaluation eines schulungsprogramms für studenten im praktischen jahr in der Inneren medizin [Development and evaluation of a training scheme for final year students in internal medicine]. GMS Z Med Ausbild.2006;23(4):Doc70. German.

35. Cook AF, Arora VM, Rasinski KA, Curlin FA, Yoon JD. The prevalence of medical student mistreatment and its association with burnout. Acad Med. 2014;89(5):749-754.

36. Hagemeier NE, Hess R Jr, Hagen KS, Sorah EL. Impact of an interprofessional communication course on nursing, medical, and pharmacy students' communication skill self-efficacy beliefs. Am J Pharm Educ. 2014;78(10): 186.

37. Dewa CS, Loong D, Bonato S, Thanh NX, Jacobs P. How does burnout affect physician productivity? A systematic literature review. $B M C$ Health Serv Res. 2014;14:325.

38. Cohen MJ, Kay A, Youakim JM, Balaicuis JM. Identity transformation in medical students. Am J Psychoanal. 2009;69(1):43-52.

39. Ishak W, Nikravesh R, Lederer S, Perry R, Ogunyemi D, Bernstein C. Burnout in medical students: a systematic review. Clin Teach. 2013; 10(4):242-245.

40. Williams D, Tricomi G, Gupta J, Janise A. Efficacy of burnout interventions in the medical education pipeline. Acad Psychiatry. 2015; 39(1):47-54.

41. Greeson JM, Toohey MJ, Pearce MJ. An adapted, four-week mind-body skills group for medical students: reducing stress, increasing mindfulness, and enhancing self-care. Explore (NY). 2015;11(3):186-192.

42. van Dijk I, Lucassen PL, Speckens AE. Mindfulness training for medical students in their clinical clerkships: two cross-sectional studies exploring interest and participation. BMC Med Educ. 2015;15(1):24.

43. Kirkman MA, Sevdalis N, Arora S, Baker P, Vincent C, Ahmed M. The outcomes of recent patient safety education interventions for trainee physicians and medical students: a systematic review. BMJ Open. 2015;5(5): $\mathrm{e} 007705$.

44. Bosse HM, Schultz JH, Nickel M, et al. The effect of using standardized patients or peer role play on ratings of undergraduate communication training: a randomized controlled trial. Patient Educ Couns. 2012;87(3):300-306.

45. Junod Perron N, Sommer J, Louis-Simonet M, Nendaz M. Teaching communication skills: beyond wishful thinking. Swiss Med Wkly. 2015; 145:w14064

46. Krautter M, Koehl-Hackert N, Nagelmann L, et al. Improving ward round skills. MedTeach. 2014;36(9):783-788.

47. Lightman E, Kingdon S, Nelson M. A prolonged assistantship for finalyear students. Clin Teach. 2015;12(2):115-120.

48. Small RM, Soriano RP, Chietero M, Quintana J, Parkas V, Koestler J. Easing the transition: medical students' perceptions of critical skills required for the clerkships. Educ Health (Abingdon). 2008;21(3):192.

49. Williams D, Tricomi G, Gupta J, Janise A. Efficacy of burnout interventions in the medical education pipeline. Acad Psychiatry. 2015;39(1): $47-54$

50. Hart JT. The Inverse Care Law. Lancet. 1971;1(7696):405-412.
Advances in Medical Education and Practice

\section{Publish your work in this journal}

Advances in Medical Education and Practice is an international, peerreviewed, open access journal that aims to present and publish research on Medical Education covering medical, dental, nursing and allied health care professional education. The journal covers undergraduate education, postgraduate training and continuing medical education

\section{Dovepress}

including emerging trends and innovative models linking education, research, and health care services. The manuscript management system is completely online and includes a very quick and fair peer-review system. Visit http://www.dovepress.com/testimonials.php to read real quotes from published authors. 